
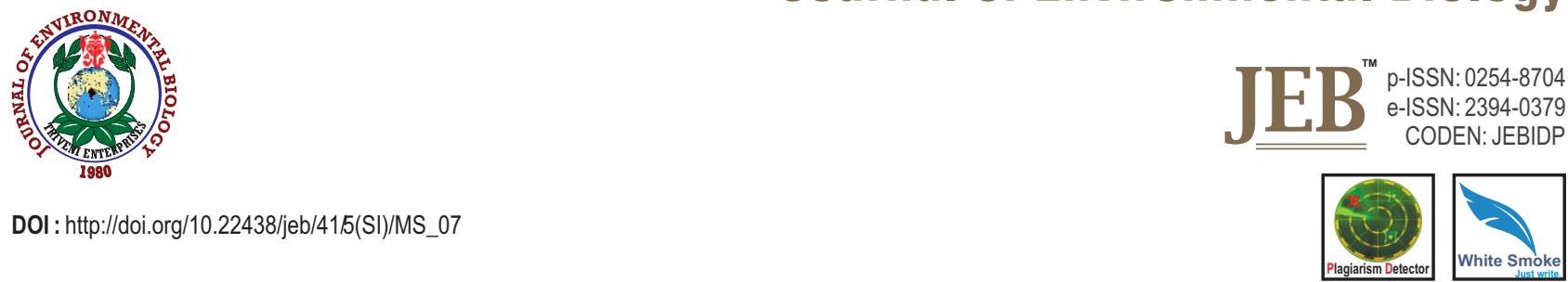

\title{
Vibrio sp. associated with acute hepatopancreatic necrosis disease (AHPND) found in penaeid shrimp pond from east cost of peninsular Malaysia
}

\author{
M.A. Amatul-Samahah ${ }^{1,2}$, S. Muthukrishnan, W.H.H.W. Omar ${ }^{3}$, N.F.M. Ikhsan ${ }^{1}$ and M.Y. Ina-Salwany ${ }^{1,3 *}$ \\ ${ }^{1}$ Department of Aquaculture, Faculty of Agriculture, Universiti Putra Malaysia, 43400 Serdang, Selangor, Malaysia \\ ${ }^{2}$ Fisheries Research Institute Gelang Patah, Department of Fisheries Malaysia, 81550, Gelang Patah, Johor, Malaysia \\ ${ }^{3}$ Laboratory of Marine Biotechnology, Institute of Bioscience, Universiti Putra Malaysia, 43400 Serdang, Selangor, Malaysia \\ *Corresponding Author Email : salwany@upm.edu.my
}

\section{Abstract}

Aim: Acute hepatopancreatic necrosis disease (AHPND) is one of the fastest emerging disease in shrimp aquaculture industry. Based on a recent AHPND case reported in our local shrimp farm, this study aimed to isolate, identify and characterize the causal agent of AHPND isolated from a shrimp farm located in Malaysia.

Methodology : The isolates were first screened with AP4 primers, then identified based on phenotypic observations and phylogenetic analysis. Screening of selected virulence genes, antibiotic susceptibility test, and virulency study of the isolates using Artemia sp. as challenge model were carried out to further distinguish each isolates.

Results : Six positive AHPND isolates were reported in this study, where four of them were identified as $V$. harveyi and another two were $V$. parahaemolyticus. All the isolates appeared to be susceptible against tetracycline. $V$. parahaemolyticus (C2A, C4B) showed higher virulency than $V$. harveyi $(\mathrm{CIB}$, C2B, C4A, D5) when tested in Artemia sp. challenge study.

Interpretation : This study reports that, in Malaysia, both $V$. parahaemolyticus and $V$. harveyi could be the causative pathogen of AHPND outbreak in local shrimp farm.

Key word : Acute hepatopancreatic necrosis disease, Aquaculture, Shrimp disease, Vibrio harveyi, Vibrio parahaemolyticus

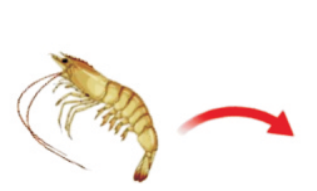

(I) Hepatopanceas of infected shrimp were collected

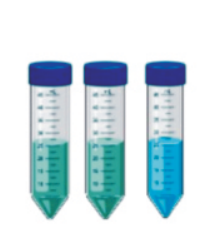

(VI) Bioassay using Artemia sp. to find thd most virulent strain

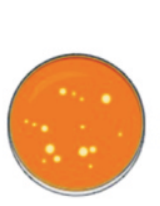

(II) Vibrio sp. were isolated and screened on TCBS. Pure culture were grown on marine agar

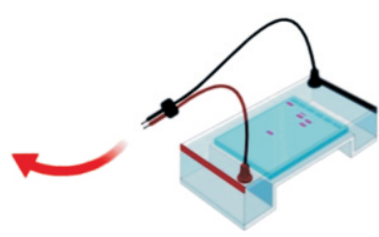

(V) Virulence gene of the isolates, assessment, tdh, trh, the, pirA ${ }^{\text {vp }}$ (toxin A) \& $\operatorname{pirB}^{\text {vp }}$ (toxin $B$ )

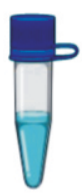

(III) Genomic DNA was

extracted and screen for positive AHPND isolate using AP4 method by Dangtip et al., 2014

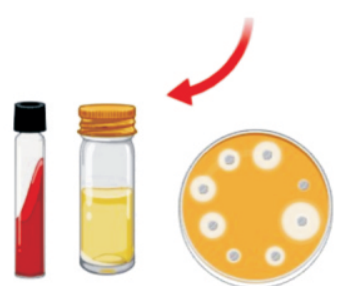

(IV) Phenotypic characterization of the AHPND positive isolate; biochemical test and antibiotic susceptibility analysis

How to cite : Amatul-Samahah, M.A., S. Muthukrishnan, W.H.H.W. Omar, N.F.M. Ikhsan and M.Y. Ina-Salwany: Vibrio sp. associated with acute hepatopancreatic necrosis disease (AHPND) found in penaeid shrimp pond from east cost of peninsular Malaysia. J. Environ. Biol., 41, 1160-1170 (2020). 


\section{Introduction}

Acute hepatopancreatic necrosis disease (AHPND) is an alarming threat to the shrimp aquaculture industry. AHPND impose a serious threat to the shrimp production, and globally it has been reported to cause a loss of USD 1 billion to the shrimp industries (Leaño and Mohan, 2012a). AHPND was first ever reported in Southern China in 2009 (Zhang et al., 2012). Shortly after that, the disease was reported in Vietnam in 2010 (Lighter et al., 2012). Subsequently, Malaysia in 2011 (Chu et al., 2016; Lighter et al., 2012), Thailand in 2012 (Leaño and Mohan, 2012b), Mexico in 2013 (Soto-Rodriguez et al., 2015), Philippines in 2015 (Dabu et al., 2015) and United States of America, USA in 2017 (Dhar et al., 2019). Malaysia has felt the impact as outbreak of AHPND in whiteleg shrimp farms in 2011, 2012 and 2013 has caused a significant reduction of shrimp production to 67,000 metric tonne, 55,000 metric tonne, and 50,000 metric tonne in 2011, 2012 and 2013, respectively (Annual Fisheries Statistics, 2005-2014). Based on the estimation of shrimp production losses from year 2011 to year 2014, the economic losses from AHPND episodes were estimated to reach USD 0.49 billion (Chu et al., 2016).

Vibrio parahaemolyticus has been reported the causative agent AHPND in shrimp (Joshi et al., 2014; Tran et al., 2013). However, not all strains of $V$. parahaemolyticus cause APHND. Only those acquired pVA1 plasmid which encodes toxins are able to cause AHPND (Lee et al., 2015). The bacteria with this plasmid produces and releases toxins that is homologous to the Pir (Photorhabdus insect-related) toxin which consists of two subunits, PirA ${ }^{v p}$ and PirB ${ }^{\text {vp }}$ (Sirikharin et al., 2015). Though, predominantly $V$. parahaemolyticus has been reported as the main causal bacteria for the disease (Joshi et al., 2014; Tran et al., 2013), findings of the past ten years has shown that other Vibrio sp. can also carry the pVA1 plasmid which encodes the AHPND binary toxins (Lee et al., 2015). Studies have reported that the plasmid carrying the virulence plasmid has also been found in $\mathrm{V}$. harveyi (Kondo et al., 2015), V. owensii (Liu et al., 2015) and V. campbelli (Dong et al., 2017). In a more recent findings, the AHPND virulent plasmid was found in V. punensis sp. nov. strain $B A 55$ which belongs to the Orientalis clade, marking for the first time that a virulence plasmid found in species other than Harveyi clade (Restrepo et al., 2018).

Both environmental stress and the presence of causative agent, $V$. parahaemolyticus, are important factors for AHPND outbreaks in culture ponds (Akazawa and Eguchi, 2017). It is hypothesized that shrimps acquire infection by consuming raw sludge contaminated with the pathogen from the bottom of culture pond. Fluctuation in the $\mathrm{pH}$ of pond water causes stress and has weakened the immune system of white shrimp (Li and Chen, 2008). Other environmental influences such as temperature and salinity can also induce the occurrence AHPND (Moullac and Haffner, 2000).
This disease affectes postlarvae and juvenile shrimp upon the first 20 to 30 days of stocking in grow-out pond (Lightner et al., 2012; Tran et al., 2013). Based on the observations, slow growth, loose shells and discoloration are the early clinical signs of this disease (Leaño and Mohan, 2012b). Pathologically, it degenerates hepatopancreas (sloughing of the hepatopancreas tubule epithelial cells), hemocytic infiltration, necrosis, and eventually death of the post larvae and juvenile shrimp (Tran et al., 2013). It has been reported that this disease has incurred great loss to farmers as it causes mass mortalities up to $100 \%$ of PLs during the first 20 to 30 days after stocking (Tran et al., 2013).

Based on a recent AHPND case reported in our local shrimp farm, in Terengganu, Malaysia, this study was carried out to isolate, identify and characterize the causal pathogen of AHPND from Malaysian shrimp farm. The bacterial virulency of the isolated strains were also determined using brine shrimp as the infection model to understand and compare the characteristics of AHPND causal Vibrio sp. strain found in Malaysia.

\section{Materials and Methods}

The sampling was carried out in a shrimp farm, in Setiu, Terengganu located in the east coastal area of the peninsular Malaysia on $11^{\text {th }}$ and $12^{\text {th }}$ May, 2017. The farmers has reported the incidents of massive death of shrimp in a few newly stocked farm. Post larvae shrimp, Penaeus vannamei, at of approximately $5 \mathrm{~g}$ from ponds with mortalities were sampled. The shrimp was sampled based on the abnormal gross signs consistent to AHPND symptoms. Such signs inclusive of pale to whitish hepatopancreas with reduction in size.

In this study, hepatopancreas of the AHPND infected shrimp were aseptically separated, crushed and inoculated into flasks containing marine broth (Sigma, USA). The flasks were kept at $27^{\circ} \mathrm{C}$ for 18 to $24 \mathrm{hr}$ to culture the pathogens. Individual colonies from the mix cultures were re-cultured on thiosulfatecitrate-bile salts-sucrose (TCBS) agar supplemented with 1.5\% sodium chloride and kept at $27^{\circ} \mathrm{C}$ for $24 \mathrm{hr}$. The colony morphologies were observed, and then each colonies were cultured into tryptone soy broth (TSB) to confirm pure culture and were streaked again onto TCBS agar plates. All single isolates were stocked in tryptone soy broth (TSB) pre-added with $20 \%$ glycerol and stored at $-80^{\circ} \mathrm{C}$ for other usages.

Genomic DNA extraction was done using GeneJET Genomic DNA Purification Kit, Thermo Scientific (USA). A single colony was inoculated into $10 \mathrm{ml}$ marine broth, and kept for $18 \mathrm{hr}$ at $27^{\circ} \mathrm{C}$. The cells were then spin-downed by centrifugation at $5000 \mathrm{~g}$, for $10 \mathrm{~min}$. The bacterial DNA extraction, GeneJET Genomic DNA Purification Kit was done as stated in the manual provided. Screening for AHPND positive strains were carried out using AP4 method. AP4 method is a two-step nested PCR 
screening of AHPND isolates (Dangtip et al., 2015). The method targeted the tandem genes of pirA ${ }^{\text {vp }}$ and pir ${ }^{\text {vp }}$ on pVA plasmid (Lee et al., 2015). The primers used in this method comprised of two pairs as stated in Table 1. PCR mixtures consisted of 5 PCR buffer, $2.0 \mu \mathrm{l} \mathrm{MgCl}_{2}(100 \mathrm{mM}), 1.0 \mu \mathrm{dNTPs}$ (10 mM each), $1.0 \mu \mathrm{l}$ each forward and reverse primers $(20 \mu \mathrm{M}), 0.5$ GoTaq Polymerase $\left(5{\mathrm{U} \mu \mathrm{l}^{-1}}^{-1}\right.$ ) (Promega, USA), $5.0 \mu$ l of DNA template

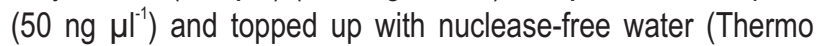
Fisher Scientific, USA) making up the final volume of $25 \mu \mathrm{l}$ per reaction. PCR programmes were conducted using Eppendorf ${ }^{\mathrm{TM}}$ Mastercycler ${ }^{\mathrm{TM}}$ Nexus Thermal Cycler (Germany). The nested thermal PCR reactions consisted of two step, in the first step, PCR amplifications were carried out by the following programme: denaturation $94^{\circ} \mathrm{C}$ for 2 min then 30 cycles; each cycle, $94^{\circ} \mathrm{C}$ for $30 \mathrm{sec}, 55^{\circ} \mathrm{C}$ for $30 \mathrm{sec}$, and $72^{\circ} \mathrm{C}$ for $90 \mathrm{sec}$, then the final elongation step at $72{ }^{\circ} \mathrm{C}$ for 2 min. For the second step of nested PCR, amplifications were done as follows: denaturation $94^{\circ} \mathrm{C}$ for 2 min then 25 cycles; each cycle, $94^{\circ} \mathrm{C}$ for $30 \mathrm{sec}, 55^{\circ} \mathrm{C}$ for $30 \mathrm{sec}$, and $72^{\circ} \mathrm{C}$ for $90 \mathrm{sec}$, then the final elongation step at $72^{\circ} \mathrm{C}$ for 2 min. Further confirmation using duplex PCR was done to amplify pirA and pirB genes, which are unique to AHPND isolates. The PCR programme for duplex $P C R$ carried out for pirA and pirB was as follows: denaturation $94^{\circ} \mathrm{C}$ for 3 min followed by 35 cycles; each cycle $94^{\circ} \mathrm{C}$ for $30 \mathrm{sec}, 60^{\circ} \mathrm{C}$ for $30 \mathrm{sec}$, and $72^{\circ} \mathrm{C}$ for $30 \mathrm{sec}$, then the final elongation step at $72^{\circ} \mathrm{C}$ for $7 \mathrm{~min}$. Amplified PCR fragments were analysed by agarose gel electrophoresis (1.0\%).

Table 1: Summary of set of primers used in this study

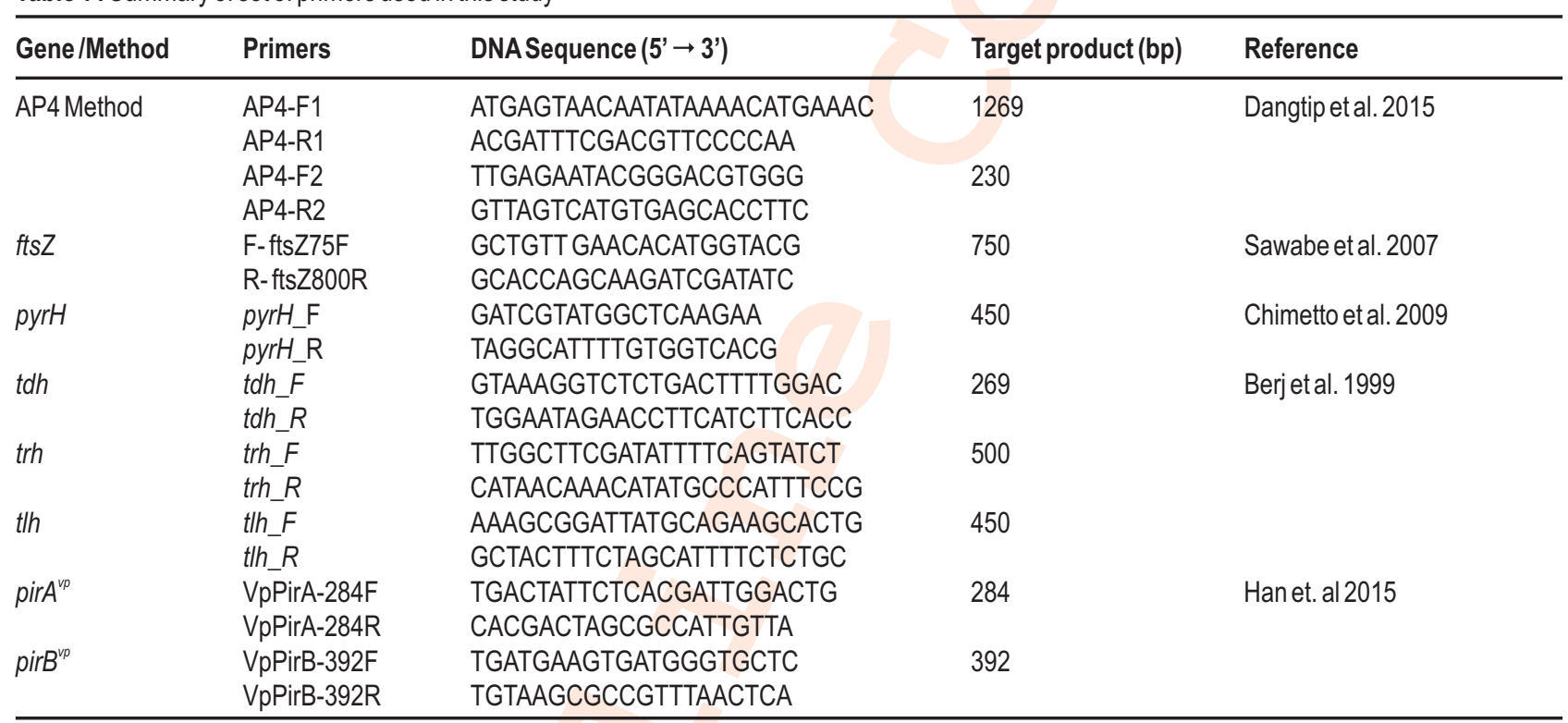

Table 2 : Phenotypic and biochemical characterization of AHPND positive isolates

\begin{tabular}{|c|c|c|c|c|c|c|c|c|c|}
\hline \multirow{2}{*}{$\begin{array}{l}\text { Isolates } \\
\text { code }\end{array}$} & \multicolumn{8}{|c|}{ Phenotypic observation } & \multirow[t]{2}{*}{ Identified species } \\
\hline & Gram staining & TCBS & Oxidase & Catalase & TSI & $\begin{array}{l}\text { Lysinede } \\
\text { carboxylase }\end{array}$ & ONPG & $\begin{array}{l}\text { Hemolysin } \\
\text { activity }\end{array}$ & \\
\hline $\mathrm{C} 1 \mathrm{~B}$ & Negative, rod shaped & Yellow & + & + & $\mathrm{A} / \mathrm{A}$ & + & + & y & V. harveyi \\
\hline $\mathrm{C} 2 \mathrm{~A}$ & Negative,rod shaped & $\begin{array}{l}\text { Green bluish, } \\
\text { pigmented }\end{array}$ & + & + & $\mathrm{K} / \mathrm{A}$ & + & + & y & V. parahaemolyticus \\
\hline $\mathrm{C} 2 \mathrm{~B}$ & Negative,rod shaped & Yellow & + & + & $\mathrm{A} / \mathrm{A}$ & + & + & y & V. harveyi \\
\hline C4A & Negative, rod shaped & Yellow & + & + & $\mathrm{A} / \mathrm{A}$ & + & + & y & V. harveyi \\
\hline C4B & Negative,rod shaped & $\begin{array}{l}\text { Green bluish, } \\
\text { pigmented }\end{array}$ & + & + & $\mathrm{K} / \mathrm{A}$ & + & + & y & V. parahaemolyticus \\
\hline D5 & Negative,rod shaped & Yellow & + & + & $\mathrm{A} / \mathrm{A}$ & + & + & y & V. harveyi \\
\hline
\end{tabular}

Note : No gas production were observed for TSI analysis. $\alpha$-hemolysis, $\alpha$-hemolysin partially breaks down the red blood cells and leaves a greenish color; $\beta$-hemolysis, beta-hemolysin breaks down the red blood cells and hemoglobin completely, a clear zone around the bacterial growth; $\gamma$-hemolysis, does not produce hemolysins and does not break down the blood cells, no clearing will occur 
Electrophoresis gel were viewed under the Alpha Imager (USA). $1 \mathrm{~kb}$ Plus DNA Ladder (Thermofisher Scientific) were used as a guide to determine the amplicon size.

To screen the positive isolates of Vibrio having AHPND virulency, phylogenetic analysis were carried out using $\mathrm{fts} Z$ and pyrH gene. Identification of positive AHPND isolates was performed by using primers as stated in Table 1. PCR reactions were inclusive of $5.0 \mu \mathrm{lPCR}$ buffer, $2.0 \mu \mathrm{l} \mathrm{MgCl}(100 \mathrm{mM}), 1.0 \mu \mathrm{l}$ dNTPs (10 mM each), $1.0 \mu \mathrm{l}$ each forward and reverse primers $(20 \mu \mathrm{M}), 0.5 \mathrm{GoTaq}$ (Promega, USA) Polymerase $\left(5 \mathrm{U} \mu \mathrm{l}^{-1}\right), 5.0 \mu \mathrm{l}$

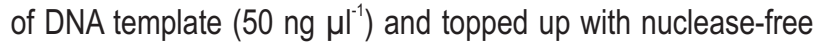
water (Thermo Fisher Scientific, USA) to make up the final volume of $25 \mu \mathrm{l}$. For amplification of partial ftsZ gene, the PCR programme was started with denaturation at $94^{\circ} \mathrm{C}$ for $3 \mathrm{~min}$ followed by 30 cycles; each cycle; $94^{\circ} \mathrm{C}$ for $1 \mathrm{~min}, 53.8^{\circ} \mathrm{C}$ for $1 \mathrm{~min}$ and $72^{\circ} \mathrm{C}$ for $1 \mathrm{~min}$, then the final elongation step was carried out at $72^{\circ} \mathrm{C}$ for $5 \mathrm{~min}$. Meanwhile, for amplification of partial pyrH gene, temperature-cycling programme was carried out, denaturation at $94^{\circ} \mathrm{C}$ for 3 min followed by 30 cycles; each cycle, $94^{\circ} \mathrm{C}$ for $1 \mathrm{~min}, 50.9^{\circ} \mathrm{C}$ for $1 \mathrm{~min}$ and $72^{\circ} \mathrm{C}$ for $1 \mathrm{~min}$, then the final elongation step at $72^{\circ} \mathrm{C}$ for $5 \mathrm{~min}$. All PCR fragments were analysed for sequencing by MEGAversion 7.0.

Gram staining was carried out with Gram staining set kit (Merck, USA). Growth and colonial pigmentation were observed on TCBS (Oxoid, USA). Oxidase test was performed using oxidase strips (Oxoid, USA). Catalase test by catalase reagent (Sigma-Aldrich). Triple sugar iron agar (TSI) (Oxoid, USA) test was performed to characterize sugar fermenters and hydrogen sulphide production. Besides that, lysine decarboxylase test (Oxoid, USA) was carried out by culturing the isolate in decarboxylase broth. Ortho-Nitrophenyl- $\beta$-galactoside (ONPG) test was also performed to identify $\beta$-galactosidase activity of the isolates. All analysis were carried out according to manual supplied by the manufacturers. Observations were based on colour changes occurred before and after the test carried out. All the AHPND positive isolates were then characterize to their susceptibility to different types of antibiotics (Table 3 ) using disk diffusion method as stated in the Clinical and Laboratory Standards Institutes (CLSI, 2015) on Mueller-Hinton agar (MHA). Antibiotics discs (Oxoid, UK) were put onto the agar and kept at $27^{\circ} \mathrm{C}$ for 18 to $24 \mathrm{hr}$. The zone of inhibitions were observed and the diameters were recorded. The acceptable susceptible zone of inhibition values for antibiotics (Table 3) used were based on (CLSI, 2015). All AHPND positive isolates were subjected to hemolytic activity screening. A single colony culture from each isolate were inoculated onto blood agar and kept for $24 \mathrm{hr}$ at $27^{\circ} \mathrm{C}$. The type of hemolysin was determined by pigmentation production and hemolysis area on the plate agar.

All positive AHPND isolates were assessed for virulence gene analysis. Multiplex PCR were used to amplify thermostable direct hemolysin (tdh), TDH-related hemolysin (trh) and thermolabile haemolysin (th). PCR mixtures composed of $5.0 \mu \mathrm{l}$ of PCR buffer, $2.0 \mu \mathrm{l}$ of $\mathrm{MgCl}_{2}(100 \mathrm{mM}), 1.0 \mu$ lof dNTPs (10 mM each), $1.0 \mu \mathrm{l}$ of each forward and reverse primers $(20 \mu \mathrm{M}), 0.5 \mu \mathrm{l}$ GoTaq) Polymerase (Promega, USA) $\left(5 \cup \mu l^{-1}\right), 5.0 \mu$ l of template $\left(50 \mathrm{ng} \mathrm{\mu l}^{-1}\right.$ ) and topped up with nuclease-free water (Thermo Fisher Scientific, USA) to make up the final volume of $25 \mu$ l. Meanwhile, the programme for multiplex PCR for $t d h$, trh and th amplification were as follows: denaturation at $94{ }^{\circ} \mathrm{C}$ for $3 \mathrm{~min}$ followed by 30 cycles; each cycle, $94^{\circ} \mathrm{C}$ for $1 \mathrm{~min}, 58^{\circ} \mathrm{C}$ for $1 \mathrm{~min}$, and $72^{\circ} \mathrm{C}$ for $1 \mathrm{~min}$, then the final elongation step at $72^{\circ} \mathrm{C}$ for 5 min. Amplified DNA fragments were analysed by agarose gel electrophoresis $(1.0 \%)$ and ethidium bromide staining. Electrophoresis gel were viewed under the Alpha Imager (USA).

Table 3 : Acceptable susceptible zone of inhibition values for antibiotics used based on CLSI (2015)

\begin{tabular}{|c|c|c|c|c|}
\hline \multirow[t]{2}{*}{ Antibiotic } & \multirow[t]{2}{*}{ Concentration } & \multicolumn{3}{|c|}{ Zone diameter interpretive criteria (nearest whole, $\mathrm{mm}$ ) } \\
\hline & & Susceptible & Intermediate & Resistance \\
\hline Ampicilin (AMP) & $10 \mu \mathrm{g}$ & $\geq 17$ & $14-16$ & $\leq 13$ \\
\hline Bacitracin (B) & 10 units & $\geq 13$ & - & - \\
\hline Cefepime (FEP) & $30 \mu g$ & $\geq 25$ & $19-24$ & $\leq 18$ \\
\hline Cefriaxone (CRO) & $30 \mu g$ & $\geq 23$ & $20-22$ & $\leq 19$ \\
\hline Chloramphenicol $(\mathrm{C})$ & $30 \mu \mathrm{g}$ & $\geq 18$ & $13-17$ & $\leq 12$ \\
\hline Ciprofloxacin (CIP) & $5 \mu g$ & $\geq 21$ & $16-20$ & $\leq 15$ \\
\hline Cephalothin (KF) & $30 \mu \mathrm{g}$ & $\geq 18$ & $15-27$ & $\leq 14$ \\
\hline Erythromycin (E) & $15 \mu \mathrm{g}$ & $\geq 23$ & $14-22$ & $\leq 11$ \\
\hline Gentamicin (CN) & $10 \mu \mathrm{g}$ & $\geq 15$ & $13-14$ & $\leq 12$ \\
\hline Kananmycin (K) & $30 \mu g$ & $\geq 18$ & $14-17$ & $\leq 13$ \\
\hline Streptomycin (S) & $25 \mu \mathrm{g}$ & $\geq 15$ & $12-14$ & $\leq 11$ \\
\hline Tetracycline (TE) & $30 \mu \mathrm{g}$ & $\geq 15$ & $12-14$ & $\leq 11$ \\
\hline Vancomycin (VA) & $30 \mu \mathrm{g}$ & $\geq 17$ & $15-16$ & $\leq 14$ \\
\hline
\end{tabular}

${ }^{*}$ CLSI: Clinical and Laboratory Standards Institute, 2015. 
Virulency study of all the AHPND positive isolates was carried out using brine shrimp, Artemia sp. (Mermaid, China). Before the challenge, $50 \mu \mathrm{l}$ of stock bacterial culture were transferred into $5 \mathrm{ml}$ Marine broth were kept overnight at $28^{\circ} \mathrm{C}$ under constant agitation (180 rpm). All the equipments used in this study were autoclaved at $120^{\circ} \mathrm{C}$ for $20 \mathrm{~min}$ prior to use and all culturing activities were carried out under a laminar flow hood with axenic conditions. Hatching of brine shrimp larvae were performed as per Defoirdt et al. (2005). A $200 \mathrm{mg}$ of Artemia sp. cysts was soaked in $18 \mathrm{ml}$ distill water for $1 \mathrm{hr}$ with strong filtered aeration through $0.22 \mu \mathrm{m}$ filter to avoid bacterial contamination. After hydration, $660 \mu$ l of sodium hydroxide $(30 \% \mathrm{w} / \mathrm{v})$ and $10 \mathrm{ml}$ of sodium hypochlorite $(17.3 \% \mathrm{w} / \mathrm{v})$ were added to initiate the decapsulation process. The reaction of decapsulation were stopped after $120 \mathrm{sec}$ by adding $14 \mathrm{ml}$ of autoclaved sodium thiosulphate pentahydrate $(1 \% \mathrm{w} / \mathrm{v})$ into the mixture. Decapsulated cysts were washed with $1 \mathrm{I}$ of filtered autoclaved artificial sea water and the cysts were collected over a $100 \mu \mathrm{m}$ sterile sieve. Decapsulated cysts were transferred to sterile $50 \mathrm{ml}$ falcon tubes pre-added with $30 \mathrm{ml}$ of marine broth. The tubes with decapsulated cysts were placed on a rotor (4 rpm), constantly exposing to incandescent light (2000 lux) at $28^{\circ} \mathrm{C}$ for $24 \mathrm{hr}$ for hatching. The hatched Artemia sp. nauplii was used for challenge trials. For the challenge activity, each isolate suspension was inoculated into each $50 \mathrm{ml}$ Falcon tubes pre-added with 20 nauplii in $20 \mathrm{ml}$ seawater. The challenge trial was carried out at three

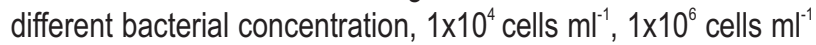
and $1 \times 10^{8}$ cells $\mathrm{ml}^{-1}$ in triplicates. The falcon tubes were kept at $28^{\circ} \mathrm{C}$ and monitoring was carried out every $12 \mathrm{hr}$ to check survival of Artemia nauplii. Survival percentage was calculated to determine the most virulence isolate. Statistical significance of data between groups was evaluated by Analysis of variance (ANOVA), while multiple comparisons were made by Tukey tests. $P$-value $<0.05$ was considered significant.

\section{Results and Discussion}

Generally, the symptoms showed by AHPND infected shrimp were consistent as those previously reported (Tran et al., 2013). Lethargy, notably smaller size, discolouration of shrimp and hepatopancreas turning whitish have been observed (Leaño and Mohan, 2012b; Soto-Rodriguez et al., 2015; Tran et al., 2013). Thirty three isolates were isolated from the hepatopancrease of diseased shrimp. Fifteen isolates that showed growth on TCBS were further screened with AP4 primers to identify the presence of AHPND virulence genes. Based on all the isolates screened with AP4 method, six isolates showed positive results and the isolates were coded as $\mathrm{C} 1 \mathrm{~B}, \mathrm{C} 2 \mathrm{~A}, \mathrm{C} 2 \mathrm{~B}$, C4A, C4B and D5.

AP4 method is widely used to detectAHPND cases (Dabu et al., 2015; Dhar et al., 2019). This method has been carefully designed and gives 100\% confirmation for AHPND-causing isolates (Sritunyalucksana et al., 2015). As compared to the predecessor method used, this method has been devised to achieve minimum sensitivity as low as $1 \mathrm{fg}$ of DNA only. This enables direct detection of AHPND-causing isolates on tissue samples and environmental samples (water, sludge and sediment) that may have low to very low level of AHPND bacteria (Dangtip et al., 2015). The designation of the method were based on the toxins that contributed uniquely to the virulency of this disease which consists of two subunits, PirA ${ }^{\text {vp }}$ and PirB ${ }^{\text {vp }}$ (Lee et al., 2015; Han et al., 2015; Sirikharin et al., 2015). The causative pathogen of AHPND, V. parahaemolyticus (Lee et al., 2015) carries a pVA1 plasmid containing both virulent toxin genes, pirA and pirB. Though, $V$. parahaemolyticus was the first Vibrio species found to carry the plasmid (Sirikharin et al., 2015), other Vibrio species have been also reported to carry the virulent plasmid (Dong et al., 2017; Kondo et al., 2015; Liu et al., 2015; Restrepo et al., 2018) and recent findings evidently show the occurrence of horizontal transfer of pVA1 plasmid in between Vibrio species (Dong et al., 2019). However, it is still debatable to pin-point which Vibrio species is the original carrier of plasmid as Wangman et al. (2018) had discovered both PirA and PirB toxins in an archived $V$. campbelli, isolated seven years before the first case of AHPND occurred in 2009 in China (Zhang et al., 2012).

Phylogenetic analyses were carried out using neighbourjoining method to confirm their taxonomic position in the genus Vibrio. Based on the phylogenetic analysis using fts $Z$ gene, $C 2 A$ and $C 4 B$ were clustered with $V$. parahaemolyticus and $C 1 B, C 2 B$, $\mathrm{C} 4 \mathrm{~A}$ and D5 were clustered with $\mathrm{V}$. harveyi (Fig. 1). Phylogenetic analysis using pyrH gene also showed $\mathrm{C} 2 \mathrm{~A}$ and $\mathrm{C} 4 \mathrm{~B}$ clustered with $V$. parahaemolyticus and $\mathrm{C} 1 \mathrm{~B}, \mathrm{C} 2 \mathrm{~B}, \mathrm{C} 4 \mathrm{~A}$, and $\mathrm{D} 5$ clustered with $V$. harveyi (Fig. 2). Both analysis were carried out using neighbour-joining (Kimura 2-parameter model) of concatenated phylogenetic tree. Both $\mathrm{ftsZ}$ and $\mathrm{pyrH}$ were commonly used in multilocus sequence analysis (MLSA) (Al-Saari et al., 2015; Hoffman et al., 2012; Sawabe et al., 2013; Steinum et al., 2016; Tanaka et al., 2018; Thompson et al., 2007). Both gene codes for housekeeping genes, ftsZ a cell division protein and $\mathrm{pyrH}$, urydilate kinase and were also among the genes that gave the highest resolution in distinctively differentiating $V$. harveyi and $V$. campbelli (Thompson et al., 2007). Both genes were used along with other genes to confirm a novel Vibrio species, $V$. caribbeanicus sp. nov (Hoffman et al., 2012), Vibrio tritonus sp. nov (Sawabe et al., 2013) and to construct the phylogeny of Rumoiensis clade species (Al-Saari et al., 2015), a relatively new clade of Vibrionaceae (Sawabe et al., 2013). According to Steinum et al. (2016), multilocus sequence analysis similarities for all eight genes used (including fts $\mathrm{Z}$ and $\mathrm{pyrH}$ ), were between $97.5 \%$ to $99.0 \%$ and this percentage is well above the $95 \%$ threshold to distinguish between Vibrio species as proposed by Sawabe et al. (2007).

All the isolates were negative and rod shaped (Table 2). This indicated that all the six isolates belonged to Gram-negative bacteria. The growth and colonal pigmentation of six isolates 


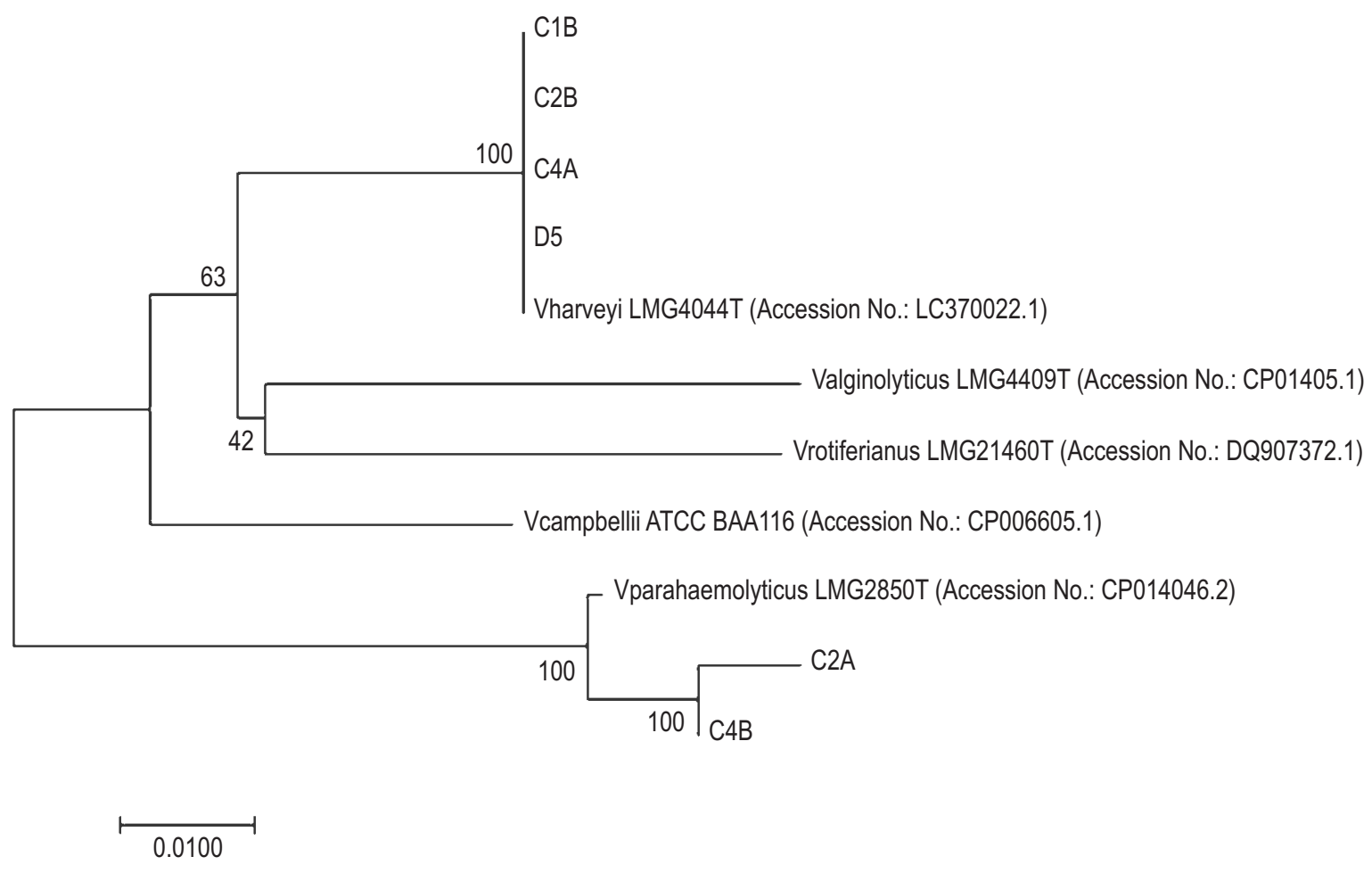

Fig. 1 : Neighbor-joining phylogeny (Kimura 2-parameter model) of concatenated partial ftsZ gene sequences from Vibrio sp. strains. Bootstrap values represent 1,000 replications. Reference sequences were acquired from the NCBI GenBank.

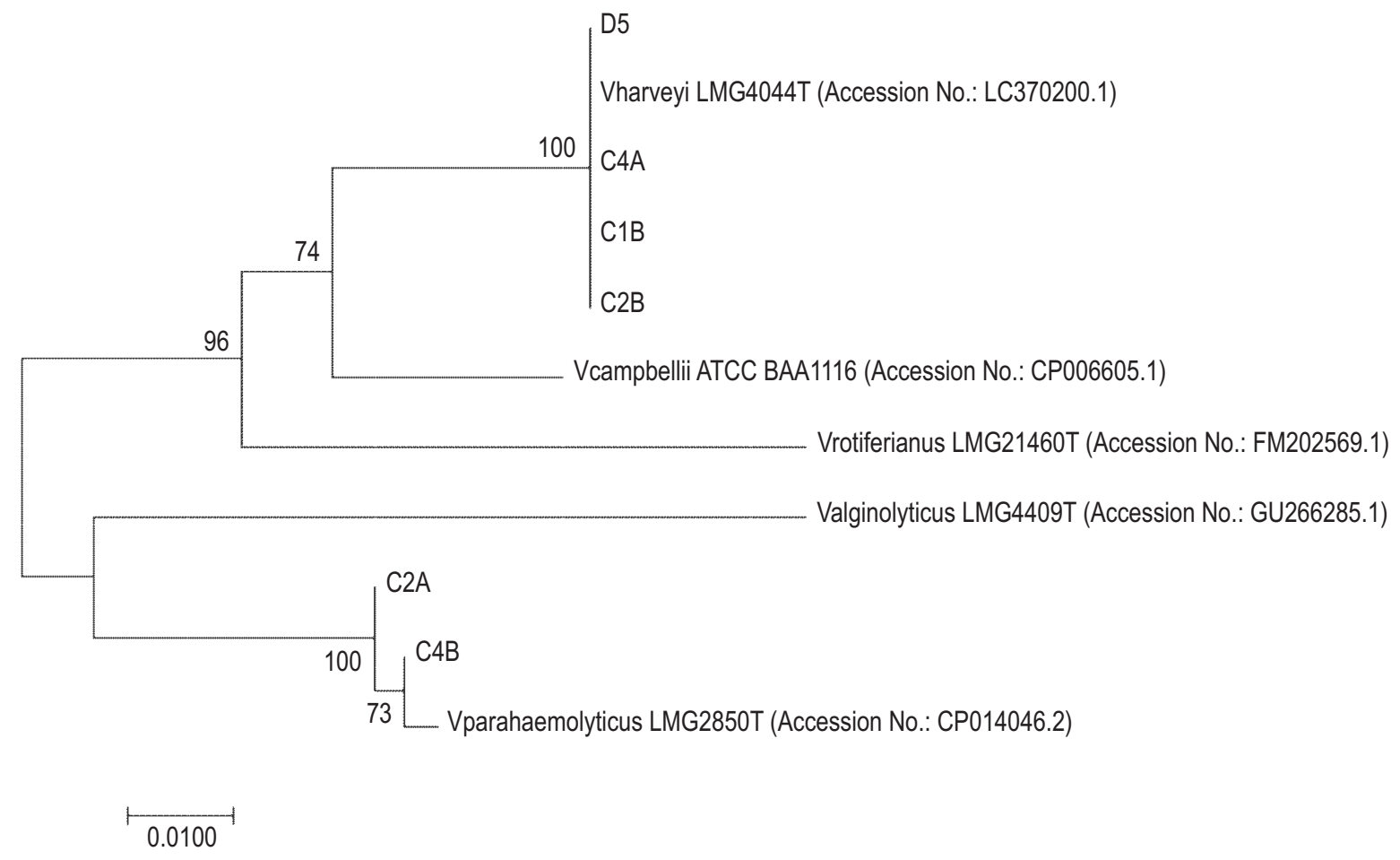

Fig. 2 : Neighbor-joining phylogeny (Kimura 2-parameter model) of concatenated partial pyrH gene sequences from Vibrio sp. strains. Bootstrap values represent 1,000 replications. Reference sequences were acquired from the NCBI GenBank. 
Table 4 : Antibiotic resistance profile and MAR index of AHPND positive isolates to thirteen antibiotics

\begin{tabular}{|c|c|c|c|c|c|c|c|c|c|c|c|c|c|c|c|}
\hline $\begin{array}{l}\text { Isolate } \\
\text { code }\end{array}$ & Species & AMP & B & FEP & CRO & C & CIP & KF & $E$ & $\mathrm{CN}$ & $\mathrm{K}$ & S & TE & VA & MAR Index \\
\hline $\mathrm{CIB}$ & V. harveyi & $\mathrm{R}$ & $\mathrm{R}$ & $\mathrm{R}$ & I & $S$ & $S$ & $S$ & $\mathrm{R}$ & $S$ & $S$ & $S$ & S & $\mathrm{R}$ & 0.4 \\
\hline $\mathrm{C} 2 \mathrm{~A}$ & V. parahaemolyticus & $S$ & $\mathrm{R}$ & $S$ & $S$ & $S$ & I & I & I & $S$ & $S$ & $S$ & S & $\mathrm{R}$ & 0.2 \\
\hline $\mathrm{C} 2 \mathrm{~B}$ & V. harveyi & $S$ & $S$ & $\mathrm{R}$ & $\mathrm{R}$ & $S$ & i & $S$ & i & $S$ & $S$ & $\mathrm{R}$ & S & $S$ & 0.2 \\
\hline C4A & V. harveyi & $S$ & $S$ & $\mathrm{R}$ & $\mathrm{R}$ & S & $S$ & । & I & $\mathrm{R}$ & $\mathrm{R}$ & $\mathrm{R}$ & S & $S$ & 0.4 \\
\hline C4B & V.parahaemolyticus & $\mathrm{R}$ & $\mathrm{R}$ & $S$ & $S$ & $S$ & I & $S$ & I & $S$ & $S$ & $S$ & S & $\mathrm{R}$ & 0.2 \\
\hline D5 & V. harveyi & S & $\mathrm{R}$ & $S$ & $\mathrm{R}$ & $\mathrm{R}$ & i & $S$ & $\mathrm{R}$ & $S$ & $S$ & $S$ & S & I & 0.3 \\
\hline \multicolumn{2}{|c|}{ Total isolates tested } & 6 & 6 & 6 & 6 & 6 & 6 & 6 & 6 & 6 & 6 & 6 & 6 & 6 & \\
\hline \multicolumn{2}{|c|}{ Total resistance isolates } & 2 & 4 & 3 & 3 & 1 & 0 & 0 & 2 & 1 & 1 & 2 & 0 & 3 & \\
\hline \multirow{2}{*}{\multicolumn{2}{|c|}{$\begin{array}{l}\text { Percentage of resistance } \\
\text { isolates (\%) }\end{array}$}} & 33.3 & 66.7 & 50.0 & 50.0 & 16.7 & 0.0 & 0.0 & 33.3 & 16.7 & 16.7 & 33.3 & 0.0 & 50.0 & \\
\hline & & $(2)$ & (4) & (3) & (3) & (1) & $(0)$ & $(0)$ & (2) & (1) & (1) & $(2)$ & (0) & (3) & \\
\hline \multirow{2}{*}{\multicolumn{2}{|c|}{$\begin{array}{l}\text { Percentage of intermediate } \\
\text { resistance isolates }(\%)\end{array}$}} & 0.0 & 0.0 & 0.0 & 16.7 & 0.0 & 66.7 & 33.3 & 66.7 & 0.0 & 0.0 & 0.0 & 0.0 & 16.7 & \\
\hline & & (0) & $(0)$ & (0) & (1) & (0) & (4) & (2) & (4) & (0) & (0) & (0) & (0) & (1) & \\
\hline \multirow{2}{*}{\multicolumn{2}{|c|}{$\begin{array}{l}\text { Percentage of susceptible } \\
\text { isolates }(\%)\end{array}$}} & 66.7 & 33.7 & 50.0 & 50.0 & 83.3 & 33.7 & 66.7 & 0.0 & 83.3 & 83.3 & 66.7 & 100.0 & 33.3 & \\
\hline & & (4) & (2) & (3) & (3) & (5) & (2) & (4) & (0) & (5) & (5) & (4) & (6) & $(2)$ & \\
\hline
\end{tabular}

Note: Symbol "R": resistant, "l": intermediate "S": susceptible, AMP: ampicillin, B: bacitracin, FEP: cefepime, CRO: ceftriaxone, C: chloramphenicol, CIP: ciprofloxacin, KF: cephalothin, E: erythromycin, CN: gentamicin, K: kananmycin, S: streptomycin, TE: tetracyclin, VA: vancomyci

Table 5 : Presence of virulence genes in AHPND positive isolates

\begin{tabular}{llllll}
\hline Isolates & \multicolumn{5}{c}{ Virulence index } \\
\cline { 2 - 6 } & pirA & pirB & + & tdh & trh \\
\hline C1B & + & + & - & - & th \\
C2A & + & + & - & - & - \\
C2B & + & + & - & - & + \\
C4A & + & + & - & - & + \\
C4B & + & + & - & - & + \\
D5 & + & & - & & + \\
\end{tabular}

observed on TCBS agar revealed that, four out of six isolates showed growth and formed yellow colonies and another two isolates showed growth and formed green-bluish pigmented colonies. The oxidase and catalase test of all isolates were positive (Table 2). Triple Sugar Iron Test was used to detect bacterial ability to ferment lactose, sucrose and glucose and their ability to produce $\mathrm{H}_{2} \mathrm{~S}$ (Farmer and Hickman-Brenner, 1992). Based on the TSI results, two isolates produced alkaline-overacid reaction (K/A) and another four produced acid-over-acid reaction $(A / A)$. No gas production observed during TSI analysis. All the isolates were positive for the lysine decarboxylase test and ONPG test. Based on the phenotypic characterization, two of the positive isolates were $V$. parahaemolyticus and another four were V. harveyi. Table 2 showed the results of haemolysin analysis of all the isolates. All the isolates showed $\mathrm{y}$-hemolysis, as no breakdown of blood cells occurred (no clearing occur).

Thirteen antibiotics were used to screen the antibiotic susceptibility of isolates (Table 3). Based on the results (Table 4), $66.6 \%(n=6)$ of all the isolates showed resistancy towards bacitracin. This was the highest resistancy observed among all the tested antibiotics. $50.0 \%(n=6)$ resistancy against cefepime, ceftriaxone and vancomycin. Only $33.3 \%(n=6)$ of the isolates were resistance against ampicillin, erythromycin and streptomycin. $16.7 \%(n=6)$ of the isolates recorded against chloramphenicol, gentamicin and kananmycin. No resistancy was observed against ciprofloxacin, cephalothin and tetracycline. Multiple antibiotic resistance (MAR) were calculated for all the antibiotics. MAR index more than 0.2 indicates that the isolates were isolated from a high risk source of exposure where antibiotics are often used (Krumperman, 1983). Three isolates $(50.0 \%)$ had MAR index greater than 0.2 . The MAR index calculated indicated that there is a potential that the isolates come from a high risk of source where antibiotics were used (Table 4). Further tests are required for larger number of isolates to confirm this. The isolates showed more than 50 percent resistancy against bacitracin, cefepime, ceftriaxone and vancomycin. It is not uncommon that in fish industry, particularly in developing countries like Malaysia, a lot of antibiotics have been used to avoid infection (Cabello et al., 2006). Though the virulency of AHPND isolates has been linked to tetracycline resistancy before (Dong et al., 2017; Han et al., 2015), all the isolates in this study 

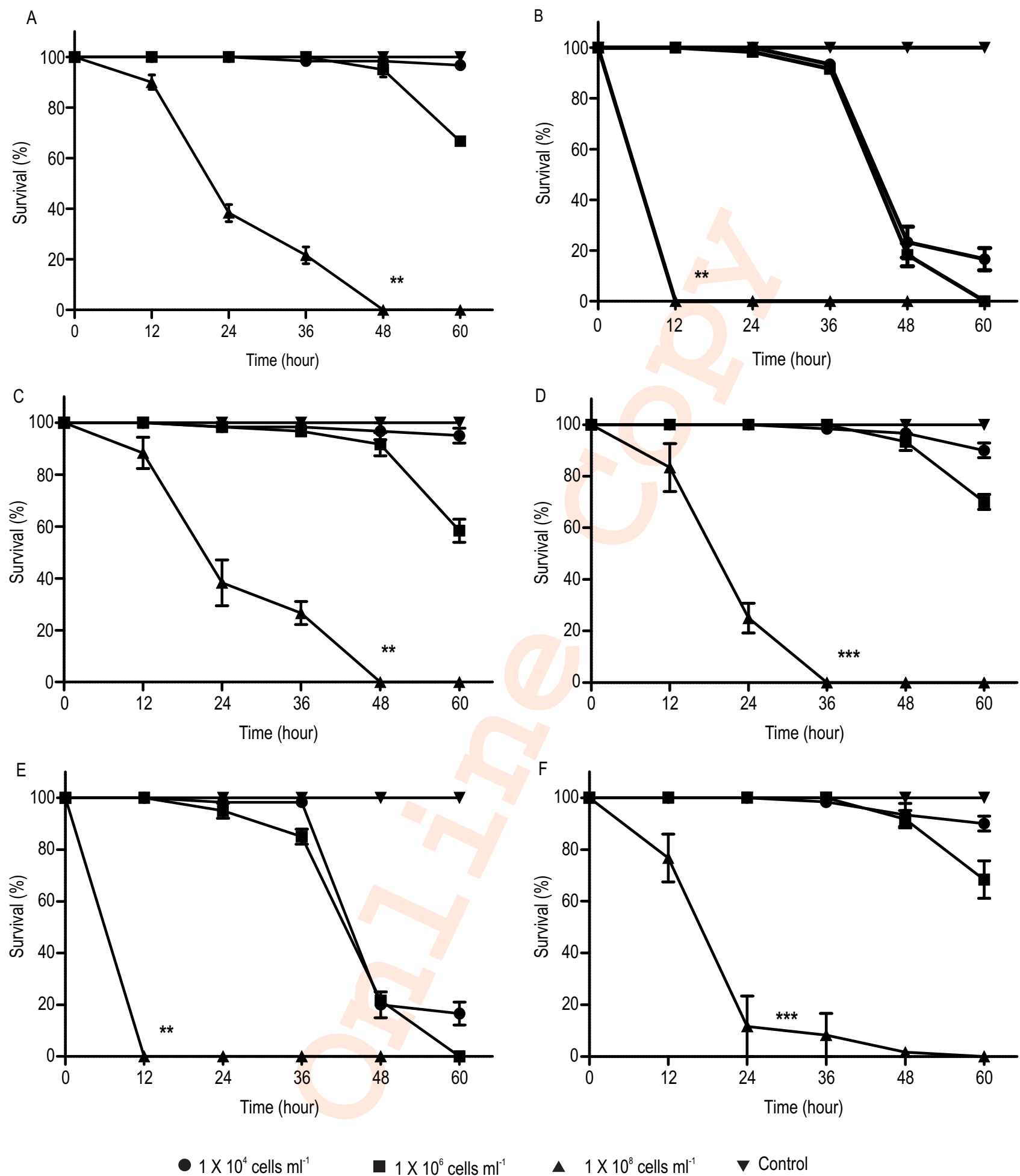

Fig. 3 : Survival (\%) of Artemiasp. nauplii after 60 hours of challenged with isolate A) C1B B) C2A C) C2B D) C4A E) C4B and F) D5 at three different bacterial concentrations; $1 \times 10^{4} \mathrm{cellsml}^{-1}, 1 \times 10^{6} \mathrm{cellsml}^{-1}$ and $1 \times 10^{8}$ cells $\mathrm{ml}^{-1}$. Control represents non-challenge group. Significant difference between challenged and control groups were evaluated at $P<.05\left(^{*}\right), P<.01\left(^{* \star}\right)$ and $\left.P<.0011^{(* *}\right)$ using one-way ANOVAanalysis.

were found susceptible against tetracycline. This is in agreement with the AHPND isolates from Vietnam that did not carry tetB and susceptible against tetracycline (Han et al., 2015). This could shed some lights to the origin of this local isolates. 


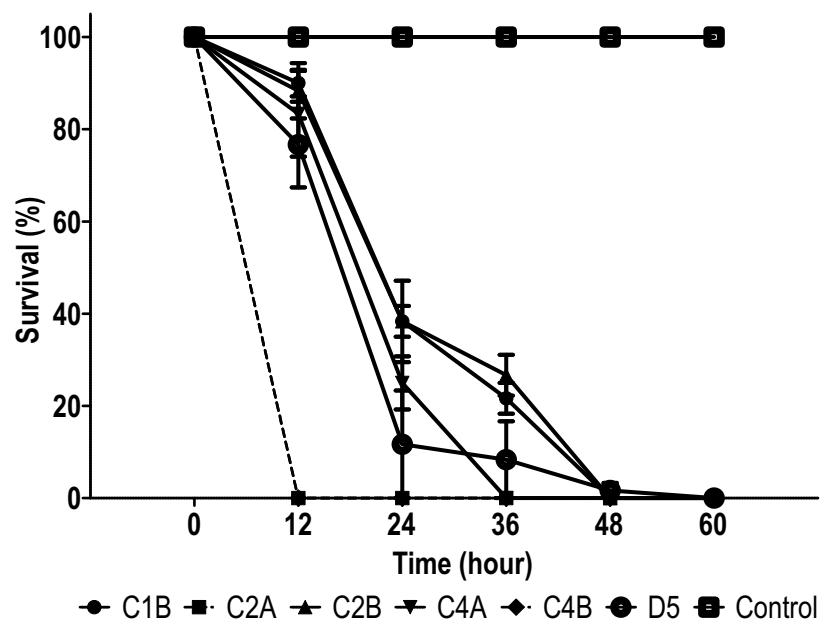

Fig. 4 : Comparison of survival (\%) of Artemia sp. nauplii at $1 \times 108$ cells $\mathrm{ml}^{-1}$ for $60 \mathrm{hr}$ of challenged with isolate C1B, C2A, C2B, C4A, $\mathrm{C} 4 \mathrm{~B}$ and $\mathrm{D} 5$. Control represents non-challenge group.

Table 5 shows the results of virulence gene screening of all the AHPND positive isolates. The isolates were screened for thermostable direct hemolysin (tdh), TDH-related hemolysin (trh) and thermolabile haemolysin (t/h). All the isolates were tdh and trh negative, and th positive. All the AHPND isolates showed negative results upon screening with thermostable direct hemolysin (tdh), TDH-related hemolysin (trh) (Miyamoto et al., 1969; Honda and Lida, 1993). This is true as these isolates were isolated from an environmental source. Observation on the hemolysin plate also showed no breakdown of blood cells occurred (no clearing occur) indicating y-hemolysis. Both these genes are actually vital for the virulency of pathogen as these genes encodes the pore-forming proteins involved in the invasiveness of pathogen. All isolates were thermolabile haemolysin gene (th) (Taniguchi et al., 1986) positive and has been reported earlier that this gene is widespread in $V$. parahaemolyticus, V. alginolyticus, V. harveyi, V. fischeri, V. mimicus, $V$. natriegens, $V$. proteolyticus, $V$. anguillarum and $V$. vulnificus (Wang et al., 2007).

As reported by Kreger and Lockwood (1981), highly virulent strains of bacteria can produce higher amount of toxins as compared to less virulent strains. The virulency study of isolates using Artemia sp. nauplii was conducted. Artemia sp. nauplii was challenged with all six positive AHPND isolates. Three different bacterial concentrations $1 \times 10^{4}$ cells $\mathrm{ml}^{-1}, 1 \times 10^{6}$ cells ml $^{-1}$ and $1 \times 10^{8}$ cells $\mathrm{ml}^{-1}$ were selected in this study. Fig. 3 shows the survival percentage of Artemia sp. challenged with all six AHPND isolates at three different bacterial concentrations. At $1 \times 10^{4}$ cells mll $^{-1}$, after $48 \mathrm{hrs}$ of challenge, isolate C2A and C4B ( $V$. parahaemolyticus), showed less than $40 \%$ survivality, as compared to other isolates (Fig. 3). Meanwhile, at $1 \times 10^{6}$ cells $\mathrm{ml}^{-1}$, after $48 \mathrm{hrs}$ of challenge, both isolates also showed less than $30 \%$ survivality as compared to other isolates (Fig. 3). All the isolates were also compared and analysed at the bacterial concentration $1 \times 10^{8}$ cells $\mathrm{ml}^{-1}$. Fig. 4 shows that Artemia sp. challenged with C2A and C4B ( $V$. parahaemolyticus) showed $100 \%$ mortality after incubation for only $12 \mathrm{hr}$. Meanwhile, Artemia sp. challenged with C1B, C2B, C4A and D5 (V. harveyi) started showing more than $100 \%$ mortality only after $48 \mathrm{hrs}$. In this study, AHPND positive isolates of $V$. parahaemolyticus showed more virulence than $V$. harveyi. In this study, $V$. parahaemolyticus was found as the most virulent isolate. However, Dong et al. (2017) demonstrated that $P$. vannamei infected with both AHPND positive $V$. parahaemolyticus and AHPND positive $V$. campbelli presented similar mortality and suggested that the pathogenicity encoded of AHPND is independent within closely related Vibrio species (Harveyiclade).

In conclusion, this study showed that, in Malaysia, both $V$. parahaemolyticus and $V$. harveyi could both be the causative pathogen of AHPND outbreak in local shrimp farm. Although after ten years of first outbreak in this country, APHND cases still occur. Looking further into the genome construction of each locally isolated species and analyzing the pathogenic plasmids would gave us more insights on how to manage and control the disease.

\section{Acknowledgments}

This research was supported by a research grant from the Ministry of Education (MOE) under the Fundamental Research Grant Scheme (FRGS) programme (Ref: FRGS/1/2018/WAB01/ UPM/02/12) and Higher Institution Centre of Excellence (HiCOE) (Vote No.: 6369100).

\section{References}

Akazawa, N. and M. Eguchi: Pond sludge and increased pH cause early mortality syndrome/acute hepatopancreatic necrosis disease (EMS/AHPND) in cultured white shrimp. BjoMSA, 1, 92-96 (2017).

Al-Saari, N., F. Gao, A.K.M.A. Rohul, K. Sato, K. Sato and S. Mino: Advanced microbial taxonomy combined with genome-basedapproaches reveals that $V$. astriarenae sp. Nov., an agarolytic marine bacterium, forms a new clade in Vibrionaceae. PLOS ONE, 10, 1-17 (2015).

Annual Fisheries Statistics. 2005-2014. Department of Fisheries Malaysia.

Bej, A.K., D.P. Patterson, C.W. Brasher, M.C.L Vickery, D.D. Jones and C.A. Kaysner: Detection of total and hemolysin-producing $V$. parahaemolyticus in shellfish using multiplex PCR amplification of tl, tdh and trh. J. Microbiol. Methods, 36, 215-225 (1999).

Cabello, F.C.: Heavy use of prophylactic antibiotics in aquaculture: A growing problem for human and animal health and for the environment. Environ. Microbiol., 8, 1137-1144 (2006).

Chu, K.B., I. Ahmad, A.S. Zahrah, J. Irene, J. Norazila, N.Y. Nik Haiha, Y. Fadzilah, M. Mohammed, B.S. Rokhaiya, M. Omar and N.P. Teoh: Current status of acute hepatopancreatic disease (AHPND) of farmed shrimp in Malaysia. In: Addresing acute hepatopancreatic necrosis disease (AHPND) and other transboundary disease for improved aquatic animal health in Southeast Asia (Eds.: R.V. Jr. Pakingking, E.G.T de Jesus-Ayson and B.O. Acosta) Tigbauan, 
Iloilo, Philippines: Aquaculture Department, Southeast Asian Fisheries Development Center, p. 55 (2016).

Chimetto, L.A., M. Brocchi, M. Gondo, C.C. Thompson, B. Gomez-Gil, and F.L. Thompson: Genomic diversity of vibrios associated with the Brazilian coral Mussismilia hispida and its sympatric zoanthids (Palythoa caribaeorum, Palythoa variabilis and Zoanthus solanderi). J. Appl. Microbiol., 106, 1818-1826 (2009).

CLSI: Performance Standards for Antimicrobial Susceptibility Testing; Twenty-Fifth Informational Supplement. CLSI. Wayne, Pennsylvania, USA(2015).

Dabu, I.M., J.J. Lim, P.M.T. Arabit, S.J.A.B. Orense, J.A. Tabardillo, V.L. Corre and M.B.B. Maningas: The first record of acute hepatopancreatic necrosis disease in the Philippines. Aquacult. Res., 48, 792-799 (2015).

Dangtip, S., R. Sirikharin, P. Sanguanrut, S. Thitamadee, K. Sritunyalucksana, S. Taengchaiyaphum, R. Mavichak, P. Proespraiwong and T. . Flegel.: AP4 method for two-tube nested PCR detection of AHPND isolates V. parahaemolyticus. Aquacult. Rep., 2, 158-162 (2015).

Defoirdt, T., P. Bossier, P. Sorgeloos and W. Verstraete: The impact of mutations in the quorum sensing systems of Aeromonas hydrophila, $V$. anguillarum and $V$. harveyi on their virulence towards gnotobiotically cultured Artemia franciscana. Environ. Microbiol., 7,1239-1247 (2005).

Dhar, A.K., P. Piamsomboon, L.F.A. Caro, S. Kanrar, R. Jr. Adami and Y.S. Juan: First report of acute hepatopancreatic necrosis disease (AHPND) occurring in the USA. Dis. Aquat. Organ., 132, 241-247 (2019).

Dong, X., D. Bi, H. Wang, P. Zou, G. Xie, X. Wan, Q. Yang, Y. Zhu, M. Chen, C. Guo, Z. Liu, W. Wang and J. Huang: pirAB ${ }^{\text {vp }}$-Bearing V. parahaemolyticus and $V$. campbelli pathogens isolated from the same AHPND-affected pond possess high similar pathogenic plasmids. Front. Microbiol., 8, 1-9 (2017).

Dong, X., J. Chen, J. Song, H. Wang, W. Wang, Y. Ren, C. Guo, X. Wang, K. F. J. Tang, and J. Huang: Evidence of the horizontal transfer of pVA1-type plasmid from AHPND causing $V$. campbellii to nonAHPND V. owensii. Aquaculture, 503, 396-402 (2019).

Farmer, J.J. and F.W. Hickman-Brenner: The General Vibrio and Photobac-terium, in The Prokaryotes. Vol. 3, Springer-Verlag, NY (1992).

Han, J.E., K.F.J. Tang, L.H. Tran and D.V. Lightner: Photohabdus insectrelated (Pir) toxin-like genes in a plasmid of $V$. parahaemolyticus, the causative agent of acute hepatopancreatic necrosis disease (AHPND) of shrimp. Dis. Aquat. Organ., 113, 33-40 (2015).

Hoffman, M., S.R. Monday, M.W. Allard, E.A. Strain, P. Whittaker, M. Naum, P.J. McCarthy, J.V. Lopez, M. Fischer and E.W. Brown: V. carribbeanicus $s p$. nov., isolated from the marine sponge Scleritoderma cyanea. Int. J. Syst. Evol. Microbiol., 62,1736-1743 (2012).

Honda, T., and T. lida: The pathogenicity of $V$. parahaemolyticus and the role of the thermostable direct haemolysin and related haemolysins. Clin. Microbiol. Rev., 4,106-113 (1993).

Joshi, J., J. Srisala, V.H. Truong, I.T. Chen, B. Nuangsaeng, 0. Suthienkul, C.F. Lo, T.W. Flegel, K. Sritunyalucksana and S. Thitamadee: Variation in $V$. parahaemolyticus isolates from a single Thai shrimp farm experiencing an outbreak of acute hepatopancreatic necrosis disease (AHPND). Aquaculture, 428, 297-302 (2014).

Kondo, H., P.T. Van, L.T. Dang and I. Hirono: Draft genome sequence of non- $V$. parahaemolyticus acute hepatopancreatic necrosis

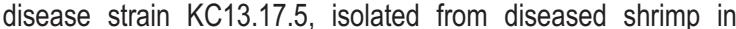
Vietnam. GenomeAnnounc., 3, 1-2 (2015).

Kreger, A.S. and D. Lockwood: Detection of extracellular toxin(s) produced by V. vulnificus. Infect. Imun., 33, 583-590 (1981).

Krumperman, P. H.: Multiple antibiotic resistance indexing of Escherichia coli to identify high-risk sources of fecal contamination of foods. Appl. Environ. Microbiol., 46,165-170 (1983).

Le Moullac, G. and P. Haffner: Environmental factors affecting immune response in Crustacea. Aquaculture, 191,121-131 (2000).

Leaño, E.M. and C.V. Mohan: Early mortality syndrome threatens Asia's shrimp farms. GAA, 8, 38-39 (2012a).

Leaño, E.M. and C.V. Mohan: Emerging threat in the Asian Shrimp Industry: Early Mortality Syndrome (EMS)/Acute Hepatopancreatic Necrosis Syndrome (AHPNS). Network of Aquaculture Centres in Asia-Pacific. Asian Fisheries Society (2012b).

Lee, C.T., I.T. Chen, Y.T. Yang, T.P. Ko, Y.T. Huang, J.Y. Huang, M.F. Huang, S.J. Lin, C.Y. Chen, S.S. Lin, D.V. Lightner, H.C. Wang, A.H.J. Wang, H.C. Wang, L.I. Hor and C.F. Lo: V. parahaemolyticus: An opportunistic marine pathogen becomes virulent by acquiring a plasmid that expresses a deadly toxin. Proc. Natl. Acad. Sci., 112, 10798-10803 (2015).

Li, C.C. and J.C. Chen: The immune response of white shrimp $L$. vannamei and its susceptibility to $\mathrm{V}$. alginolyticus under low and high pH stress. Fish Shellfish Immunol., 25, 701-709 (2008).

Lightner, D.V., R.M. Redman, C.R. Pantoja, B.L. Noble and L. Tran: Early mortality syndrome affects shrimp in Asia. GAA, 15, 40-41 (2012).

Liu, L., J. Xiao, X. Xia, Z. Pan, S. Yan and Y. Wang: Draft genome sequence of $V$. owensii strain SH-14, which causes shrimp acute hepatopancreatic necrosis disease. Genome Announc., 3, 1 (2015).

Miyamoto, Y., T. Kato, S. Obra, S. Akiyama, K. Takaziwa and S. Yamai: In vitro characteristics of $V$. parahaemolyticus: Its close correlation with human pathogenicity. J. Bacteriol., 100, 1147-1149 (1969).

Nunan, L., D. Lightner, C. Pantoja and S. Gomez-Jimenez: Detection of acute hepatopancreatic necrosis disease (AHPND) in Mexico. Dis. Aquat. Organ., 111, 81-86 (2014).

Restrepo, L., B. Bayot, S. Arciniegas, L. Bajana, I. Betancourt, F. Panchana and A.R. Munoz: PirVP genes causing AHPND identified in a new Vibrio species ( $V$. punensis) within the commensal Orientalis clade. Sci. Rep., 8, 13080 (2018).

Saravanan, V., H. Sanath-Kumar and I. Karunasagar: Putative virulence genes of $V$. cholerae from seafoods and the coastal environment of Southwest India. Int. J. Food Microbiol., 119, 329-333 (2007).

Sawabe, T., K. Kita-Tsukamoto and F.L. Thompson: Inferring the evolutionary history of vibrios by means of multilocus sequence analysis. J. Bacteriol., 189, 7932-7936 (2007).

Sawabe, T., Y. Ogura, Y. Matsumura, G. Feng, A.K.M.R. Amin, S. Mino, S. Nakagawa, T. Sawabe, R. Kumar, Y. Fukui, M. Satomi, R. Matsushima, F. L. Thompson, B. Gomez-Gil, R. Christen, F. Maruyama, K. Kurokawa and T. Hayashi: Updating the Vibrio clades defined by multilocus sequence phylogeny: proposal of eight new clades, and the description of $V$. trinotinus sp. nov. Front. Microbiol., 4, 1-14 (2013).

Sirikharin, R., S. Taengchaiyaphum, P. Sanguanrut, T.D. Chi, R. Mavinchak and P. Proespraiwong: Characterization and PCR detection of binary, Pir-like toxins from V. parahaemolyticus isolates that cause acute hepatopancreatic necrosis disease (AHPND) in shrimp. PLOS ONE, 10, 1-16 (2015). 
Soto-Rodriguez, S.A., B. Gomez-Gil, R. Lazano-Olvera, M. BetancourtLazano and M.S. Morales-Convarrubias: Field and experimental evidence of $V$. parahaemolyticus as the causative agent of acute hepatopancreatic necrosis disease of cultures shrimp ( $L$. vannamei) in northwestern Mexico. Appl. Environ. Microbiol., 81, 1689-1699 (2015).

Sritunyalucksana, K., S. Dangtip, P. Sanguanrut, R. Sirikharin, S. Taengchaiyaphum, S. Thitamadee, R. Mavichak, P. Proespraiwong and T.W. Flegel: A two-tube, nested PCR detection method for AHPND bacteria. Network of Aquaculture Centres in Asia-Pacific (NACA) (2015)

Steinum, T.M., S. Karatas, N.T. Martinussen, P.M. Meirelles, F.L. Thompson and D.J. Colquhoun: Multi-locus sequence analysis of the close relatives V. anguillarum and V. ordaii. Appl. Environ. Microbiol., 82, 5496-5504 (2016).

Tanaka, M., S. Mino, Y. Ogura, T. Hayashi and T. Sawabe: Availability of nanopore sequences in the genome taxonomy for Vibrionaceae systematics: Rumoiensis clade species as a test case. Peer. J., 6 , 1-12 (2018).

Taniguchi, H., H. Hirano, S. Kubomura, K. Higashi and Y. Mizuguchi: Comparison of the nucleotide sequences of the genes for the thermolabile hemolysin from V. parahaemolyticus. Microb. Path., 1,425-432 (1986).

Thompson, F.L., B. Gomez-Gil, A.T. Vasconcelos and T. Sawabe: Multilocus sequence analysis reveals that $V$. harveyi and $V$. campbelli are distinct species. Appl. Environ. Microbiol., 73, 4279$4285(2007)$.

Tran, L., L. Nunan, R.M. Redman, L.L. Mohney, C.R. Pantoja, K. Fitzsimmons and D.V. Lightner: Determination of the infectious nature of the agent of acute hepatopancreatic necrosis syndrome affecting penaeid shrimp. Dis. Aquat. Organ., 105, 45-55 (2013).

Wang, X.H., X.H. Zhang, Y.B. Zhong, B.G. Sun and J.X. Chen: Genes encoding the $V$. harveyi haemolysin ( $v h h$ )/thermolabile haemolysin (th) are widespread in vibrios. Acta Microbiol. Sin., 47, 874-881 (2007).

Wangman, P., S. Longyant, S. Taengchaiyaphum, S. Senapin, P. Sithigorngul and $\mathrm{P}$. Chaivisuthangkura: Pir A\& B toxins discovered in archived shrimp pathogenic $V$. campbellii isolated long before EMS/AHPND outbreaks. Aquaculture, 497, 494-502 (2018).

Zhang, B.C., F. Liu, H.H. Bian, J. Liu, L.Q. Pan and J. Huang: Isolation, identification, and pathogenicity analysis of a $V$. parahaemolyticus strain from L. vannamei. Prog. Fish. Sci.,3, 56-62 (2012). 